\title{
EFFECTS OF SPRAYING STRATEGIES BASED ON MONITORED DISEASE RISK ON GRAPE DISEASE CONTROL AND FUNGICIDE USAGE IN MARLBOROUGH
}

\author{
R.H. AGNEW ${ }^{1}$, D.C. MUNDY ${ }^{1}$ and R. BALASUBRAMANIAM ${ }^{2}$ \\ ${ }^{1}$ HortResearch, Marlborough Wine Research Centre, P.O. Box 845, Blenheim, \\ New Zealand \\ ${ }^{2}$ Delegat's Wine Estate, P.O. Box 305, Blenheim, New Zealand \\ Corresponding author: ragnew@hortresearch.co.nz
}

\begin{abstract}
Standard practice for grape disease management in Marlborough 10 years ago was to spray for diseases using calendar based spray programmes. Communication of grape disease management research has led to a change of practice for many grape growers. The key tool developed by the research programme was targeted spraying for diseases. This involved field monitoring for diseases and the use of decision support software, which contained the Bacchus Botrytis cinerea risk model. Adoption of targetbased spraying resulted in a reduction in fungicide usage of up to $50 \%$. The research involved industry consultation, field trials on vineyards and communication of information to participants. The involvement of grape growers as advocates from the outset ensured that there was industry ownership of the outcomes. A change in practice by the Marlborough grape industry has resulted in financial savings for growers and environmental benefits for the wider community through reduced fungicide applications to wine grapes.
\end{abstract}

Keywords: grape disease management, monitoring, Bacchus, target-based spraying.

\section{INTRODUCTION}

Two of the most serious diseases affecting wine grapes in New Zealand are botrytis bunch rot (Botrytis cinerea) and powdery mildew (Uncinula necator). Control of these diseases has traditionally relied on combinations of protective and curative fungicides applied on a routine calendar basis (Balasubramaniam et al. 1995). A three-year research programme was initiated to develop an integrated disease management system (IDMS) to manage botrytis bunch rot and powdery mildew of wine grapes and to reduce fungicide usage by 10-30\% (Agnew et al. 2003a). An integrated disease management system aims to manage diseases by targeting fungicides on a "need to" basis.

The routine application of protective fungicides for control of botrytis bunch rot assumes that infection risk is constant throughout the season. However, botrytis bunch rot epidemics in Marlborough are highly dependent on the occurrence of wet weather and therefore disease development is often limited during prolonged dry periods when conditions suitable for infection do not occur. A weather-based B. cinerea infection risk model known as 'Bacchus' (Balasubramaniam et al., unpubl. data) takes into account the fact that the duration of wetness required for disease development is shorter at higher temperatures. The potential of minimising fungicide use by using this model and the effect of hand leaf plucking on botrytis bunch rot were assessed.

Control of powdery mildew has generally been achieved by the application of up to four demethylation inhibitor (DMI) sprays per season. However there was potential to reduce the number and better target these sprays by developing a disease monitoring system designed to detect very low levels of powdery mildew on grape leaves and bunches. 
The application of DMI curative sprays can then be timed to coincide with powdery mildew development.

A wine growers' research consortium was formed prior to the research being undertaken and this involved personnel from each of the companies on whose properties the trials were conducted. This consortium met at regular intervals to discuss the research strategy.

\section{Trial sites and trial design}

\section{MATERIALS AND METHODS}

Trials were conducted at five vineyards in different areas of the lower Wairau Valley in Marlborough, New Zealand from 1996 to 1998. Sites were chosen from different geographical locations exhibiting variations in weather patterns and soil types. The grape variety at Site 1 was Muller Thurgau, which was machine pruned giving rise to a dense canopy. At sites 2, 3, 4 and 5 the variety was Sauvignon Blanc on a four cane vertically shoot positioned canopy. At each site the Standard spray programme used on the vineyard was compared with a 'Target' spray programme. The 'Standard' programme was determined by individual vineyard managers and varied from vineyard to vineyard, and season to season. Target spraying for powdery mildew was based on 5\% leaf and 3\% bunch incidence infection thresholds, determined through regular vineyard monitoring. Target spraying for botrytis bunch rot was based on the Bacchus infection model and growth stages susceptible to infection.

Weekly inspections of grapevines (leaves, flowers and grape berries) were made to determine the growth stage and the incidence of powdery mildew, downy mildew and botrytis bunch rot at each site. The disease assessment was performed on four adjacent rows of grapes for both the Standard and Target spray blocks. Ten alternate bays of grapes down each row were examined for disease. Within each bay 10 leaves and bunches were chosen at random on each side of the row (i.e. 20 leaves and bunches per bay). A total of 800 leaves and bunches were assessed on each of the Standard and Target blocks.

A third "leaf plucked" sub-treatment was imposed within the Target spray assessment area. Five alternate bays of grapes were hand leaf plucked in each of the four Target rows in early January when berries were pea-sized. Leaves on either side of the bunch were plucked off to fully expose bunches to light and greater air movement. A total of 400 leaves and bunches were assessed on the 20 hand leaf plucked plots.

Disease incidence was expressed as the number of leaves or bunches out of 100 showing disease. A final botrytis bunch rot severity assessment was conducted immediately prior to harvest in which the percentage of berries within individual bunches that were affected by $B$. cinerea was recorded. The mean disease severity of each treatment was calculated as:

( $\sum \%$ severity for each bunch $\div$ no. bunches assessed) $\times 100$.

Downy mildew (Plasmopara viticola) is extremely rare in Marlborough and none was recorded during the duration of the trials, hence no data is presented.

\section{Assessment of weather-based botrytis bunch rot risk}

Automated electronic weather stations accessible by telephone modems were set up at all five sites. The mesooclimate (rain, air temperature, leaf wetness, relative humidity, wind speed and wind direction) was monitored at hourly intervals. The Bacchus model was implemented in the decision support software MetWatch“ (HortPlus Ltd). This software was installed on the computers of all the consortium members and training sessions were conducted for the use of the software and downloading of the data loggers. The Bacchus model determined periods of high botrytis bunch rot risk using temperature and leaf wetness measurements from the vineyard weather stations. Dr Rengasamy Balasubramaniam and Dr Ross Edwards developed the model (Balasubramaniam et al., unpubl. data) and Mr Andrew Hodson designed the computer programme. Each consortium member entered the weekly disease monitoring results, growth stage data and spray information into their vineyard computer and ran the Bacchus model.

\section{Targeted fungicide timing decisions}

The growers made the decision to apply fungicides in response to B. cinerea infection periods and powdery mildew thresholds in consultation with the researchers. The field data was also entered into the researcher's computers to monitor weekly disease progress 
and to produce a weekly information fax service for the consortium members. Postseason feedback meetings were held to discuss the outcomes of the season's work. Records of fungicides applied, vine growth stage and disease monitoring results were kept for each vineyard site. This information, combined with the computer based Bacchus infection model, formed the basis for determining the application of sprays in the Target treatment. Sulphur sprays were applied as a protectant against powdery mildew at 2, 4 and 6 weeks after bud burst. Eight weeks after bud burst a weekly disease-monitoring programme began at each trial site. If at any stage during the season leaf powdery mildew increased above a $5 \%$ incidence threshold level, or when bunch powdery mildew levels increased above $3 \%$ incidence, a DMI spray was applied, i.e. myclobutanil (Systhane ${ }^{\circledR}$ ) or penconazole $\left(\right.$ Topas $^{\circledR}$ ). Botryticide sprays were applied to the Target treatment immediately after the Bacchus model identified $B$. cinerea infection periods at susceptible growth stages.

\section{Powdery mildew}

\section{RESULTS}

For each site and year, a disease progress curve for both leaf and bunch powdery mildew was produced from the weekly disease incidence data. The disease progress curve for leaf powdery mildew at Site 1 in the 1997/1998 season is shown in Figure 1. The dense grape canopy at this site resulted in greater powdery mildew incidence than at the other sites. In early December the incidence of powdery mildew in the Target block exceeded $5 \%$. A spray of myclobutanil (Systhane ${ }^{\circledR}$ ) was applied and disease incidence dropped below 5\%. A further two sprays were also applied at subsequent dates as disease incidence approached 5\%. Seven sprays were applied to the Target block while nine were applied to the Standard block. The disease progress curve at Site 1 had the highest and most prolonged powdery mildew incidence of the five trial sites. As a consequence more DMI applications were made at Site 1 than at the other sites.

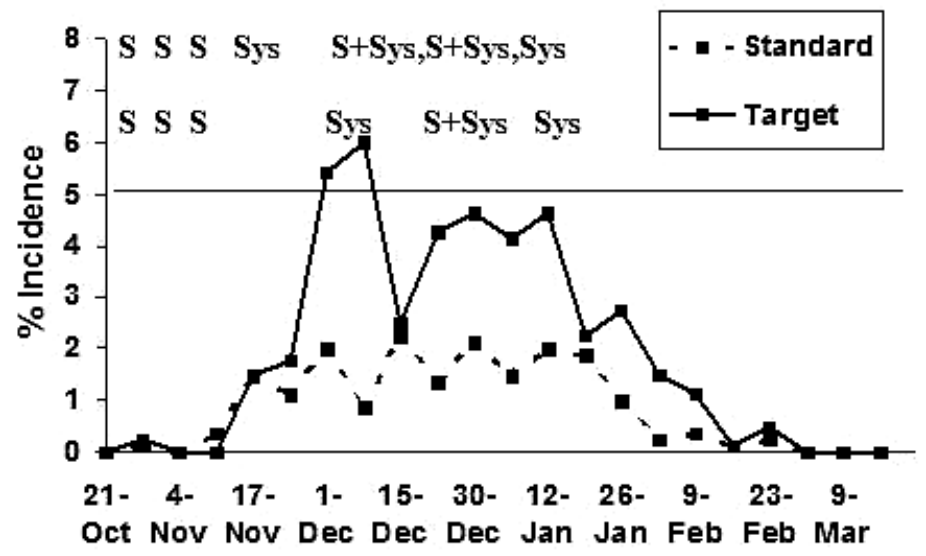

FIGURE 1: The disease progress of leaf powdery mildew on Muller Thurgau grapes at Site 1 in the 1997/1998 season. The powdery mildew fungicides applied in the Standard and Target spray programmes are indicated ( $\mathrm{S}=$ Sulphur, Sys=Systhane ${ }^{\circledR}$ ). 
The total number of powdery mildew fungicides applied at each site for the Standard and Target spray programmes over the three years of the trial is presented in Table 1. There was a trend for the number of fungicides applied to the Target blocks to decrease during the trial.

TABLE 1: Total number of powdery mildew fungicide applications in the Standard and Target spray programmes at five vineyard sites over three seasons.

\begin{tabular}{|c|c|c|c|c|c|c|}
\hline & \multicolumn{2}{|c|}{1996} & \multicolumn{2}{|c|}{1997} & \multicolumn{2}{|c|}{1998} \\
\hline & Standard & Target & Standard & Target & Standard & Target \\
\hline Site 1 & 7 & 7 & 10 & 9 & 9 & 7 \\
\hline Site 2 & 5 & 5 & 5 & 6 & 7 & 7 \\
\hline Site 3 & 10 & 7 & 12 & 7 & 7 & 6 \\
\hline Site 4 & 10 & 4 & 10 & 6 & 7 & 3 \\
\hline Site 5 & 8 & 8 & 9 & 5 & 9 & 3 \\
\hline Mean & 8.0 & $6.2(22)^{1}$ & 9.2 & $6.6(28)$ & 7.8 & $5.2(33)$ \\
\hline
\end{tabular}

${ }^{1}$ Data in parentheses denote the percentage reduction compared to the other spray programme.

\section{Botrytis}

Leaf botrytis is rarely a problem in Marlborough. Over the three seasons (19961998) leaf botrytis was only detected at one of the five sites in 1996 and only $0.1 \%$ incidence was recorded.

The mean botrytis bunch rot severity at harvest and the total number of botryticides applied for each treatment, site and year are presented in Table 2. Analysis of variance performed across all sites and years (Table 2) indicated that there was a statistically significant effect $(\mathrm{P}<0.001)$ of spray treatment on botrytis bunch rot disease severity. The LSD value $(\mathrm{P}<0.05)$ shows that there was no statistically significant difference between the Standard and Target treatments, but that the Target leaf plucked treatment resulted in lower botrytis bunch rot severity than the other two treatments. There was a statistically significant difference $(\mathrm{P}<0.05)$ in the total number of botryticides applied between the Standard and Target treatments.

A comparison of the fungicide use in the Standard and Target spray programmes in the 1997/1998 season at Site 3 is presented in Table 3. Site 3 is shown because the number of fungicides applied and the total costs were in the mid range of the five sites. At Site 3, the number of fungicides applied to the Target spray treatment was reduced by $60 \%$ for botrytis bunch rot, $14 \%$ for powdery mildew and $25 \%$ for downy mildew. An overall $31 \%$ reduction in the number of fungicides was achieved. The cost of fungicides applied to the Target spray treatment for botrytis bunch rot control was reduced by $\$ 170 /$ ha (49\%). The cost of fungicides applied to the Target spray treatment for powdery mildew control was reduced by $\$ 23 /$ ha $(16 \%)$. The cost of fungicides applied to the Target spray treatment for downy mildew control was reduced by $\$ 18 /$ ha (26\%). A total reduction of $\$ 211 /$ ha on the cost of fungicides was achieved. The cost of applying the fungicides was also reduced by $\$ 123 /$ ha, giving a total cost reduction on the Target treatment of $\$ 334 /$ ha. At the other four sites the total cost reductions on the Target spray blocks varied from $\$ 100$ to $\$ 495 /$ ha. 
TABLE 2: Mean botrytis bunch rot severity at harvest and numbers of botryticide sprays applied during the season to experimental treatments at five vineyard sites over three seasons. The same botryticide sprays were applied to the Target and Target leaf plucked treatments.

\begin{tabular}{|c|c|c|c|c|c|c|}
\hline & & \multicolumn{3}{|c|}{ botrytis bunch rot severity } & \multicolumn{2}{|c|}{ No. botryticide sprays } \\
\hline & & Standard & Target & $\begin{array}{c}\text { Target - } \\
\text { leaf plucked }\end{array}$ & Standard & Target \\
\hline \multirow[t]{3}{*}{ Site 1} & 1996 & 12.6 & 4.9 & 2.8 & 4 & 5 \\
\hline & 1997 & 4.0 & 7.1 & 2.0 & 5 & 2 \\
\hline & 1998 & 3.8 & 1.1 & 0.3 & 2 & 1 \\
\hline \multirow[t]{3}{*}{ Site 2} & 1996 & 12.9 & 6.7 & 3.3 & 6 & 5 \\
\hline & 1997 & 2.6 & 2.2 & 0.5 & 3 & 2 \\
\hline & 1998 & h.b.a. ${ }^{1}$ & h.b.a. & h.b.a. & h.b.a. & h.b.a. \\
\hline \multirow[t]{3}{*}{ Site 3} & 1996 & 4.6 & 5.3 & 2.1 & 7 & 5 \\
\hline & 1997 & 12.1 & 8.8 & 3.7 & 8 & 4 \\
\hline & 1998 & 2.8 & 5.4 & 1.5 & 5 & 2 \\
\hline \multirow[t]{3}{*}{ Site 4} & 1996 & h.b.a. & 15.1 & 7.7 & 7 & 4 \\
\hline & 1997 & 6.4 & 12.3 & 5.2 & 6 & 6 \\
\hline & 1998 & 1.6 & 6.5 & 0.5 & 3 & 2 \\
\hline \multirow[t]{4}{*}{ Site 5} & 1996 & 1.5 & 7.2 & 1.8 & 4 & 2 \\
\hline & 1997 & 0.2 & 1.0 & 0.2 & 3 & 2 \\
\hline & 1998 & 4.1 & 7.4 & 1.5 & 7 & 5 \\
\hline & Mean & 5.34 & 5.92 & 2.26 & 5.0 & $3.4(33)^{2}$ \\
\hline \multirow{2}{*}{\multicolumn{2}{|c|}{$\begin{array}{l}\text { Probability } \\
\text { LSD }\end{array}$}} & \multicolumn{3}{|c|}{$<0.001$} & \multicolumn{2}{|c|}{$=0.017$} \\
\hline & & \multicolumn{3}{|c|}{1.44} & \multicolumn{2}{|c|}{1.33} \\
\hline
\end{tabular}

${ }^{1}$ h.b.a.=harvested before assessment

${ }^{2}$ Data in parentheses denote the percentage reduction compared to the other spray programme.

TABLE 3: A cost comparison (\$/ha) of Standard and Target fungicide spray programmes at Site 3 during the $1997 / 98$ season.

\begin{tabular}{lrrrrrrr}
\hline & \multicolumn{3}{c}{ Standard spray programme } & & \multicolumn{3}{c}{ Target spray programme } \\
\cline { 2 - 4 } \cline { 7 - 8 } Disease & No. & $\begin{array}{c}\text { Fungicide } \\
\text { sprays }\end{array}$ & $\begin{array}{c}\text { Application } \\
\text { cost }\end{array}$ & & $\begin{array}{l}\text { No. } \\
\text { cost }\end{array}$ & $\begin{array}{l}\text { Fungacide } \\
\text { sprays }\end{array}$ & $\begin{array}{c}\text { Application } \\
\text { sprays }\end{array}$ \\
\hline botrytis & 5 & 349.43 & 140.00 & & $2(60)^{1}$ & $179.47(49)$ & $70.00(50)$ \\
Powdery mildew & 7 & 143.72 & 140.00 & & $6(14)$ & $120.94(16)$ & $122.50(13)$ \\
Downy mildew & 4 & 69.63 & 87.50 & & $3(25)$ & $51.38(26)$ & $52.50(40)$ \\
Total & 16 & 562.78 & 367.50 & & $11(31)$ & $351.79(37)$ & $245.00(33)$ \\
\hline
\end{tabular}

${ }^{1}$ Data in parentheses denote the percentage reduction compared to the other spray programme.

\section{DISCUSSION}

Over the course of the trial it was demonstrated that weekly disease monitoring was effective at detecting powdery mildew incidence as low as $0.5 \%$. The DMI action spray thresholds of 5\% leaf incidence and 3\% bunch incidence ensured that powdery mildew did not reach unacceptable levels. Standard spray programmes prior to the commencement of the research programme involved the application of up to four DMI sprays during the season. Subsequent to the research programme many vineyards that undertake regular vineyard monitoring and maintain an open grape canopy only apply one, or at the most two DMI sprays during the season. This study did not determine whether the application 
of powdery mildew fungicides according to monitored disease thresholds led to longterm changes in the severity of powdery mildew in the vineyards studied.

This research work was similar to extensive research trials carried out in the New Zealand apple industry. Calendar-based spray programmes for apple production were also standard practice up until 1996 (Percy 1997). Subsequent to the adoption of the Integrated Fruit Production Programme for pipfruit (NZ IFP-P), most apple growers in New Zealand have switched from a conventional spray programme to spraying based on NZ IFP-P protocols. The results of this trial indicate that by use of the Bacchus $B$. cinerea risk model to time fungicide applications, botrytis bunch rot levels in Marlborough were not significantly different to a Standard calendar based spray programme. However, the number of botryticides applied to the Target spray programme was reduced by $33 \%$. With the addition of hand leaf plucking, the botrytis bunch rot levels in Marlborough were significantly reduced. Previous apple research work demonstrated that it was possible to reduce the number of fungicide sprays by $34 \%$ and the cost of fungicides by up to $56 \%$ when curative sprays were applied based on apple black spot (Venturia inequalis) infection period information (Beresford \& Manktelow 1994).

By adopting a Target based spray programme in association with hand leaf plucking, fungicide costs can be significantly reduced. These savings were largely as a result of using fewer botryticides, as these chemicals tend to be far more expensive than those used for control of powdery mildew and downy mildew. By using one less botryticide spray, such as iprodione $\left(\operatorname{Rovral}^{\circledR}\right)$, savings of approximately $\$ 150 /$ ha can be made. However, in a year with significant Botrytis infection periods, as determined by the Bacchus model, it is possible that the cost of botryticides could slightly increase. This rarely occurs in Marlborough.

Exposure of berries to light early in the season can assist with inducing disease defence mechanisms to powdery mildew and botrytis bunch rot and minimising bunch microclimate conditions conducive to B. cinerea infections (Flaherty et al. 1992). Leaf plucking minimises the time that bunches stay wet by exposing them to greater light and air movement, thereby reducing the likelihood of $B$. cinerea infection. When these trials began, hand leaf plucking to remove leaves from around bunches was not widely practised in Marlborough. As a result of this and other trials demonstrating the effectiveness of leaf plucking on minimising botrytis bunch rot, this has become a standard industry practice (Anon. 2003).

After development and evaluation by HortResearch, the Bacchus B. cinerea risk model was incorporated as part of the MetWatch software that is available through HortPlus ${ }^{\mathrm{TM}}$ (Anon. 2000). The model is available for direct use by grape growers who access weather stations close to their respective vineyards.

As a result of this research programme the winegrowers research consortium requested that a commercial service be made available during the grape growing season to supply subscribers with information, such as weather data from vineyard met stations, disease levels in monitored vineyards, $B$. cinerea infection periods as recorded by the Bacchus model and general disease management advice. This fax/email service, called Vinefax and co-ordinated by Rob Agnew of HortResearch Marlborough, began in the 1997 season and completed its eighth season of operation in 2004 (Agnew 2001). The uptake of the research outcomes by the grape industry was very much dependent on the involvement of the industry consortium members from the outset of the research programme.

The vineyard monitoring developed as part of the research programme has contributed to the development of the Sustainable Winegrowing New Zealand (Anon. 2003) disease protocols. The adoption of the integrated disease management system as industry best practise in Marlborough has had economic benefits, with reduced fungicide and application costs, as well as environmental benefits, through reduced fungicide usage (Agnew 2003b). 


\section{ACKNOWLEDGEMENTS}

The support and funding of Technology New Zealand, Marlborough Research Centre Trust, the Marlborough Grapegrowers Association and Winegrowers of New Zealand is gratefully acknowledged. Montana Wines Ltd, Cloudy Bay Vineyards Ltd and William Crosse provided trial sites and assistance with field monitoring. Dr Robert Beresford and Philippa Stevens of HortResearch gave helpful comments and suggestions in preparation of this paper.

\section{REFERENCES}

Agnew, R.; Brook, L. 2001: Popular grape grower service. www.hortresearch.co.nz/ media/news/item/pr0061.htm (30/04/04).

Agnew, R.; Mundy, D.; Balasubramaniam, R. 2003a: Managing grape disease. Food Technology in New Zealand 38 (6): 13-15.

Agnew, R.; Mundy, D.; Balasubramaniam, R. 2003b: Grape disease management research has led to a change in industry practice in Marlborough, New Zealand. Proc. $8^{\text {th }}$ Int. Cong. Plant Path. Vol. 2, Abstract no. 14.12. p. 187.

Anon. 2000: HortPlus ${ }^{\mathrm{TM}}$ MetWatch Bacchus grape botrytis model. www.hortplus.com (30/04/04).

Anon. 2003: Sustainable Winegrowing New Zealand Manual, $4^{\text {th }}$ edition. New Zealand Winegrowers, Auckland, New Zealand. Fact sheets 10A, 10B, 10C \& Chapters $10-11$.

Balasubramaniam, R.; Foley, L.; Moore, T.: Kloosterman, P. 1995: Disease management systems work in Marlborough. Proc. N. Z. Grape and Wine Symposium 10: 49-54.

Beresford, R.; Manktelow, D. 1994: Economics of reducing fungicide use by weatherbased disease forecasts for control of Venturia inequalis in apples. N. Z. J. Crop Hort. Sci. 22: 113-120.

Flaherty, D.; Christensen, P.; Lanini, T.; Marois, J.; Phillips, P.; Wilson, L. ed. 1992: Grape pest management $2^{\text {nd }} \mathrm{ed}$. University of California, Division of Agriculture and Natural Resources, Oakland, USA. p. 64.

Percy, H.; 1997. New Zealand Integrated Fruit Production - Pipfruit. www.hortnet.co.nz/ publications/hortfacts/hf505006.htm (30/04/04). 